\title{
The Advantage of Implementation of Enhanced Recovery After Surgery (ERAS) in Acute Pain Management During Elective Cesarean Delivery: A Prospective Randomized Controlled Trial
}

This article was published in the following Dove Press journal:

Therapeutics and Clinical Risk Management

\author{
Jingru $\operatorname{Pan}^{1}{ }^{1} *$ \\ Ziqing $\mathrm{Hei}^{1}{ }^{1, *}$ \\ Liping $\mathrm{Li}^{\mathrm{I}}$ \\ Dan Zhu' \\ Hongying $\mathrm{Hou}^{2}$ \\ Huizhen $\mathrm{Wu}^{\prime}$ \\ Chulian Gong' \\ Shaoli Zhou' \\ 'Department of Anesthesiology, Third \\ Affiliated Hospital, Sun Yat-sen \\ University, Guangzhou, Guangdong, \\ People's Republic of China; ${ }^{2}$ Department \\ of Obstetrics, Third Affiliated Hospital, \\ Sun Yat-sen University, Guangzhou, \\ Guangdong, People's Republic of China \\ *These authors contributed equally to \\ this work
}

Correspondence: Shaoli Zhou;

Chulian Gong

Department of Anesthesiology, Third

Affiliated Hospital, Sun Yat-sen University,

Guangzhou, Guangdong 510630, People's

Republic of China

Tel +86-20-852522297

Fax +86-20-87580876

Email shaolizhou@।39.com;

gongchulian@163.com
Objective: The aim of this study was to test whether the implementation of an enhanced recovery after surgery (ERAS) protocol for patients undergoing elective cesarean delivery has a positive impact on the postoperative status of the patients in terms of pain management, hospital stay, hospitalization costs, and adverse reactions.

Methods: Patients who underwent elective cesarean delivery were randomized into two groups - ERAS group and control group - and the groups were managed with the ERAS protocol and traditional protocol, respectively.

Results: Compared to the control group, the ERAS group had significantly fewer patients with intraoperative nausea, pain of visual analog scale (VAS) scores, and VAS grade $>3$ during rest in the first $24 \mathrm{~h}$ and during motion in the first 24 and $48 \mathrm{~h}$ after surgery. There were no intergroup differences in the requirement of extra analgesics, the incidence of vomiting, shivering, hypotension, postoperative nausea, and pruritus. None of the patients in either group had postoperative vomiting. Patient satisfaction rated as per the VAS was significantly higher in the ERAS group than in the control group. The total length of stay, postoperative length of stay, and the cost of anesthesia in both groups were comparable. Further, the average daily hospitalization cost was significantly lower in the ERAS group than in the control group.

Conclusion: The ERAS protocol shows promise and appears to be worthwhile for widespread implementation among patients undergoing elective cesarean delivery; it was found to be beneficial in reducing the postoperative pain, incidence of intraoperative nausea, and average cost of hospitalization and also improved patient satisfaction.

Keywords: enhanced recovery after surgery, ERAS, cesarean delivery, pain

\section{Introduction}

Cesarean delivery (CD) has proven to be highly beneficial for women and newborns, and the rates of delivery by CD have witnessed a steady increase over the past few decades. ${ }^{1}$ The rate of CD in China is one of the highest in the world. ${ }^{1,2}$ The main complications of CD include pain, wound separation/infection, gastrointestinal dysfunction, and deep venous thrombosis. ${ }^{3}$ Pain is one of the most important complications since it serves as a risk factor for other complications and is the main cause of anxiety and depression among patients. ${ }^{4}$

In recent times, various protocols have been introduced for enhanced recovery after surgery (ERAS). These ERAS protocols encompass multimodal perioperative 
management principles to minimize surgical stress and potential complications, accelerate patient recovery, and achieve effective analgesia. ${ }^{5}$ ERAS protocols have been developed to address perioperative complications that cannot be resolved by a single method alone. ${ }^{6}$ The ERAS protocols involve multiple factors that work in conjunction to reinforce each other and reduce stress and cytokine levels, promote trauma repair, and reduce the rate incidence of complications. ${ }^{7,8}$ Excitingly, ERAS guideline for $\mathrm{CD}$ has been published, which included inclusive perioperative recommendations with primarily a maternal focus. $^{9-11}$ However, the concern of pain relief has not been prominent. Therefore, at our medical center, we developed a feasible ERAS protocol that combines recommendations based on these guidelines as well as our experience in our clinical practice.

In this prospective-randomized controlled study, we sought to test whether the implementation of ERAS in patients undergoing elective $\mathrm{CD}$ would be beneficial in the management of postoperative pain, hospital stay, hospitalization costs, and complications.

\section{Materials and Methods}

\section{Study Design}

The current study was planned as a randomized-controlled prospective trial. The study protocol was approved by the ethics committee of the Third Affiliated Hospital of Sun Yat Sen University, Guangzhou, China on August 8, 2019. This study has been registered in the Chinese Clinical Trial Registry (registration no.: ChiCTR1900025456, registered 26 August 2019, http://www.chictr.org.cn/showproj.aspx? proj=42067). Written informed consent was obtained from all participants of the study.

\section{Study Design and Participants}

The inclusion criteria for the study were as follows: age of 25-45 years, gestation age $>38$ weeks, scheduled for elective cesarean delivery under combined spinal and epidural anesthesia (CSEA), and surgery performed between September 2019 and November 2019. Patients were excluded from the study if they met the following criteria: history of serious dysfunction of cardiovascular, coagulation, and metabolism; contraindications to morphine or CSEA use; opioid dependence; history of gastrointestinal emptying disorders, inability to conform to the ERAS strategy, need for other surgeries along with surgery, and refusal to participate in the study.

\section{Sample Size and Randomization}

The calculation of the required sample size was based on postoperative pain intensity at rest and on motion, which was the primary outcome. Our preliminary study showed that the ratio of postoperative pain of VAS grade $>3$ at rest and on motion in $24 \mathrm{~h}$ was $34 \%$ and $65 \%$ in the control group and $17 \%$ and $42 \%$ in the ERAS group, respectively. For power of 0.8 and $\alpha=0.05$, with a dropout rate of $20 \%$, the sample size was calculated to be 119 and 84 , respectively. Therefore, the sample size required in this study was determined to be at least 119 in each group.

The patients were divided into two groups: ERAS group and control group in 1:1 ratio by a computer-generated randomization sequence. According to the group assigned, they were managed with the ERAS protocol or routine protocols separately. All the enrolled participants were provided information regarding the study during their antenatal visits. The components of the two protocols are detailed in Table 1. Only details of the protocol for their respective groups were provided to the patients. On admission, care was taken to ensure that the patients of different groups were not in the same ward.

\section{Data Collection}

The perioperative data of the patients regarding the following parameters were collected: demographic characteristics (age, weight, and height), ASA grade, parity, gestational condition, preoperative complications, and blood loss. The amount and the number of drugs used during the surgery were recorded, such as vasoactive agents, carboprost tromethamine, dexmedetomidine, and antiemetics. Further, the details regarding the patient-controlled epidural analgesia (PCEA) formula, length of stay, postoperative length of stay, and hospitalization, and anesthesia costs were noted. The patients were asked to rate their pain intensity at rest and motion according to the visual analog scale (VAS) on the first and second postoperative days. Additionally, the severity of nausea, vomiting, and pruritus was evaluated before PCEA was removed. Patient satisfaction regarding the overall hospitalization experience was graded according to the VAS.

\section{Outcomes}

The primary outcome was postoperative pain intensity, as measured using the VAS. The secondary outcomes assessed were perioperative discomfort, satisfaction score, length of stay, and hospitalization cost. 
Table I Routine Protocol and ERAS Protocol

\begin{tabular}{|c|c|c|}
\hline & Routine Protocol & ERAS Protocol \\
\hline Education/Counseling & Perioperative information was not provided in advance. & $\begin{array}{l}\text { Information on perioperative procedure, pain } \\
\text { management plan, the necessity of early feeding and } \\
\text { mobilization, lactation support services, discharge } \\
\text { criteria, follow-up schedule, etc. }\end{array}$ \\
\hline Preoperative oral intake & Fasting from midnight before surgery & $\begin{array}{l}\text { Fluid up to } 2 \mathrm{~h} \text { prior to surgery } \\
\text { Solid foods up to } 6 \mathrm{~h} \text { prior to surgery }\end{array}$ \\
\hline $\begin{array}{l}\text { Standard anesthetic } \\
\text { protocol }\end{array}$ & $\begin{array}{l}\text { Received CSEA, spinal } 5 \% \text { ropivacaine } 12.5-13.5 \mathrm{mg} \text {, and } \\
\text { epidural } 1 \% \text { lidocaine } 3 \mathrm{~mL} \text {, before PCEA started. } \\
\text { Dexmedetomidine } 0.5 \mu \mathrm{g} / \mathrm{kg} \text { pump was administration } \\
\text { only if heart rate }>90 \text { beats } / \text { min or anxiety, and without } \\
\text { any contraindications. }\end{array}$ & $\begin{array}{l}\text { Received CSEA, the same as the routine protocol. } \\
\text { Dexmedetomidine } 0.5 \mu \mathrm{g} / \mathrm{kg} \text { pump was recommended } \\
\text { after childbirth. It was avoided if there were } \\
\text { contraindications, heart rate }<60 \text { beats } / \text { min or systolic } \\
\text { blood pressure }<100 \mathrm{mmHg} \text {. }\end{array}$ \\
\hline $\begin{array}{l}\text { Postoperative pain } \\
\text { management }\end{array}$ & $\begin{array}{l}\text { PCEA for } 2 \text { days; } 2 \mathrm{mg} \text { morphine initial bolus; } 6-7 \mathrm{mg} \\
\text { morphine and } 13.5 \mathrm{mg} \text { ropivacaine diluted into } 100 \mathrm{~mL} \text { in } \\
\text { the pump, } 2 \mathrm{~mL} / \mathrm{h} \text { basal rate, } 0.5 \mathrm{~mL} \text { bolus with a } 15 \text { - } \\
\text { minute lockout }\end{array}$ & $\begin{array}{l}\text { Strict } 6 \mathrm{mg} \text { morphine in the pump; remaining points same } \\
\text { as the routine protocol }\end{array}$ \\
\hline Extra analgesics & $\begin{array}{l}\text { When pain was of VAS }>3 \text {, and the patient requested } \\
\text { extra analgesics, Tramadol } 100 \mathrm{mg} \text { intramuscular injection } \\
\text { was administered }\end{array}$ & The same as routine protocol \\
\hline Prevention of PONV & Tropisetron $5 \mathrm{mg}$ at the end of the surgery. & $\begin{array}{l}\text { Tropisetron } 5 \mathrm{mg} \text { immediately after the childbirth; other } \\
\text { antiemetics as needed }\end{array}$ \\
\hline Intraoperative oxytocin & $\begin{array}{l}\text { Oxytocin } 20 \mathrm{U} \text { dilute to } 500 \mathrm{~mL} \text {, immediately after cord } \\
\text { clamping, continuous infusion } \mathrm{I}-2 \mathrm{~h} \\
\text { Carboprost tromethamine } 250 \mu \mathrm{g} \text { intramuscular } \\
\text { injection, determined by the obstetrician }\end{array}$ & $\begin{array}{l}\text { Oxytocin controlled at } 40-60 \mathrm{drop} / \mathrm{min} \\
\text { Remaining points same as the routine protocol }\end{array}$ \\
\hline Prophylactic antibiotics & $\begin{array}{l}\text { Antibiotics administration after cord clamping } \\
\text { immediately. }\end{array}$ & Same as the routine protocol \\
\hline $\begin{array}{l}\text { Perioperative fluid and } \\
\text { blood pressure } \\
\text { management }\end{array}$ & $\begin{array}{l}\text { Preferred crystalloid infusion to reduce hypotension. } \\
\text { Phenylephrine } 50 \mu g / \text { bolus if necessary. }\end{array}$ & $\begin{array}{l}\text { Avoid overhydration. Both fluids and vasopressors to } \\
\text { counteract hypotension. Prophylactic phenylephrine } 50 \mu \mathrm{g} \\
\text { followed by CSEA. }\end{array}$ \\
\hline $\begin{array}{l}\text { Preventing intraoperative } \\
\text { hypothermia }\end{array}$ & Covering bedding without warm air blower. & $\begin{array}{l}\text { The bedding was warmed with warm air blower before } \\
\text { surgery. }\end{array}$ \\
\hline Postoperative oral intake & $\begin{array}{l}\text { Until the return of bowel function, such as flatus or } \\
\text { stools }\end{array}$ & $\begin{array}{l}\text { Early oral intake, started } 2 \mathrm{~h} \text { after surgery, start with light } \\
\text { diet less than } 200 \mathrm{~mL} \text {, and then gradually increased } \\
\text { according to gastrointestinal tolerance }\end{array}$ \\
\hline $\begin{array}{l}\text { Postoperative } \\
\text { mobilization }\end{array}$ & Mobilization as per patient's discretion & $\begin{array}{l}\text { Umbilical self-massage according to the tolerance. } \\
\text { Actively turned over } 6 \text { hours after surgery. } \\
\text { Mobilization at the bedside on the first day after surgery, } \\
\text { followed by walking in the ward. }\end{array}$ \\
\hline $\begin{array}{l}\text { Skin to skin and } \\
\text { breastfeeding }\end{array}$ & $\begin{array}{l}\text { As per patient's discretion, mostly after the anesthetic } \\
\text { wore off }\end{array}$ & $\begin{array}{l}\text { Recommend early skin-to-skin contact with the } \\
\text { newborn, immediately after back to the ward. } \\
\text { Breastfeeding within I hour after the surgery, according } \\
\text { to the baby's needs }\end{array}$ \\
\hline
\end{tabular}

Note: Hypotension was defined as mean arterial pressure decrease over $20 \%$ from the value before induction of anesthesia.

Abbreviations: PONV, postoperative nausea and vomiting; ERAS, enhanced recovery after surgery; CSEA, combined spinal and epidural anesthesia; PCEA, patient controlled epidural analgesia. 


\section{Statistical Analysis}

Statistical analyses were conducted using SPSS v22.0 software package (SPSS, Chicago, IL, USA). The data were expressed as mean \pm standard deviation or proportions. Parametric data were analyzed by analysis of variance, nonparametric data with the Mann-Whitney $U$-test, and the proportions with Fisher exact test. For all analyses, $P<0.05$ was set for statistical significance.

\section{Results}

In all, 240 parturients were enrolled in this study. Some of the patients were excluded from the study: 8 and 10 patients in the ERAS group and control group, respectively, were excluded due to unexpected emergency $C D$; 6 patients in the control group refused to follow the routine protocols. Thus, the final analysis included 104 patients in the control group and 112 patients in the ERAS group (Figure 1). Comparison of the baseline patient characteristics showed that both groups were similar in terms of the preoperative ASA score, parity, gestational week, single or twin gestation, preoperative complications, and blood loss (Table 2).

\section{Postoperative Pain VAS Score}

The same anesthesia protocol was applied for all patients, except for the PCEA formula. Patients in the ERAS group received PCEA with $6 \mathrm{mg}$ morphine, but only 55 patients in the control group received morphine of $6 \mathrm{mg}(100 \% \mathrm{vs}$. $52.88 \%, P<0.01$ ); the others required $7 \mathrm{mg}$.
Within $48 \mathrm{~h}$ of the surgery, assessment of postoperative pain was completed for all patients (Figure 2). The VAS scores of pain at both postoperative $24 \mathrm{~h}$ and $48 \mathrm{~h}$ was significantly lower in the ERAS group than in the control group, both at rest and on motion (Table 3).

Further analysis revealed that during the first $24 \mathrm{~h}$ after the $\mathrm{CD}$, significantly less patients in the ERAS group had pain of grade $>3$ as per the VAS during rest and motion. At $48 \mathrm{~h}$ after surgery, the number of patients with pain of VAS grade $>3$ on motion was significantly higher in the control group than in the ERAS group. (Figure 3).

Only one patient in each group required extra analgesics (tramadol 100mg intramuscular injection); therefore, the difference in the requirement of extra analgesics was not significant (Table 3).

\section{Intraoperative and Postoperative Conditions (Table 4)}

The dosage of conventional oxytocin and carboprost tromethamine was similar in both groups. The requirement of intraoperative dexmedetomidine in the ERAS group was considerably high.

During the operation, only 3 patients in the ERAS group experienced nausea, indicating that the incidence of nausea was significantly lower in the ERAS group than that in the control group. The incidence of vomiting was greater in the control group, although the intergroup difference was not significant $(P=0.058)$. Both groups had similar incidences of shivering and hypotension.

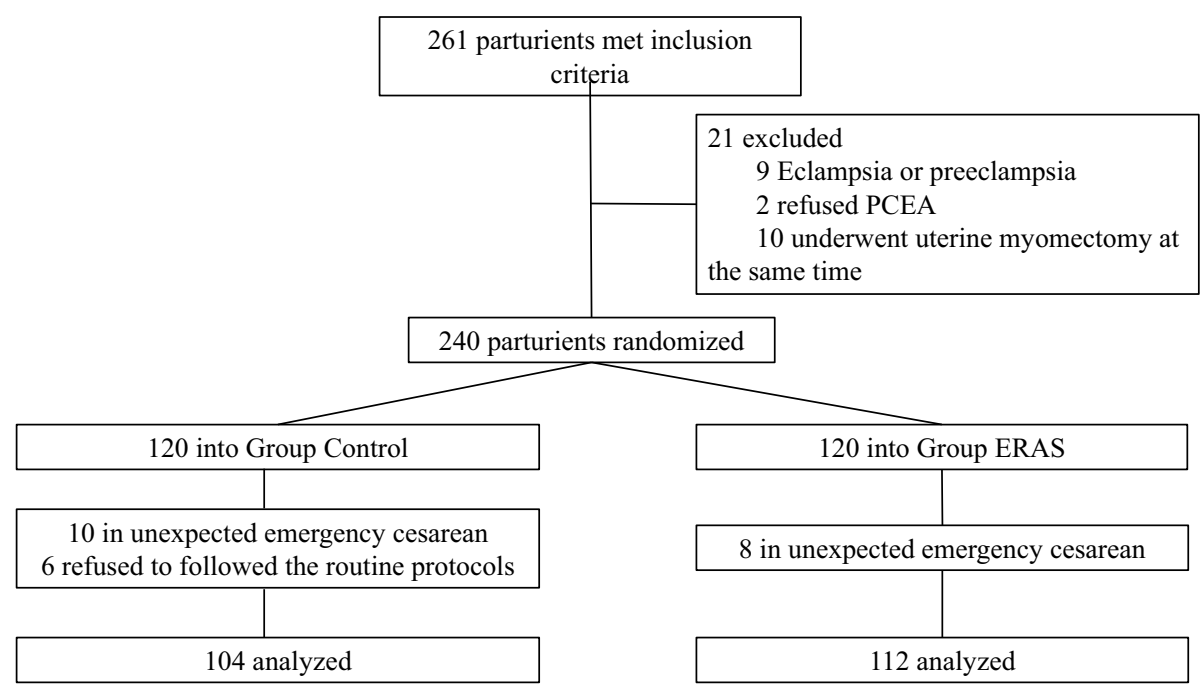

Figure I Patient enrollment and randomization. 
Table 2 Preoperative Characteristics of the Patients

\begin{tabular}{|l|l|l|l|}
\hline Characteristics & $\begin{array}{l}\text { Group } \\
\text { Control } \\
\mathbf{n}=104\end{array}$ & $\begin{array}{l}\text { Group } \\
\text { ERAS n=I I 2 }\end{array}$ & P value \\
\hline $\begin{array}{l}\text { Age (years) } \\
\text { Body mass index }\left(\mathrm{kg} / \mathrm{m}^{2}\right)\end{array}$ & $\begin{array}{l}32.59 \pm 4.14 \\
27.01 \pm 3.21\end{array}$ & $\begin{array}{l}33.21 \pm 4.49 \\
27.09 \pm 3.33\end{array}$ & 0.295 \\
\hline $\begin{array}{l}\text { ASA score } \\
\text { I }\end{array}$ & $31(29.81 \%)$ & $25(22.32 \%)$ & 0.218 \\
\hline 2 & $73(70.19 \%)$ & $87(77.68 \%)$ & \\
\hline $\begin{array}{l}\text { Parity } \\
\text { I }\end{array}$ & $28(26.92 \%)$ & $38(33.93 \%)$ & 0.302 \\
2 & $68(65.38 \%)$ & $68(60.71 \%)$ & 0.485 \\
3 and more & $8(7.84 \%)$ & $6(5.36 \%)$ & 0.585 \\
\hline Gestational week & $39.03 \pm 0.91$ & $38.96 \pm 0.91$ & 0.602 \\
\hline $\begin{array}{l}\text { Gestation } \\
\text { Single } \\
\text { Twins }\end{array}$ & $100(96.15 \%)$ & $106(94.64 \%)$ & 0.750 \\
\hline $\begin{array}{l}\text { Preoperative } \\
\text { complications }\end{array}$ & $4(3.85 \%)$ & $6(5.36 \%)$ & \\
$\begin{array}{l}\text { Thalassemia } \\
\text { Hepatitis } \\
\text { Diabetes }\end{array}$ & $27(25.96 \%)$ & $22(19.64 \%)$ & 0.330 \\
\hline $\begin{array}{l}\text { Blood loss during } \\
\text { cesarean delivery } \\
\leq 500 \mathrm{~mL} \\
>500 \mathrm{~mL}\end{array}$ & $14(13.46 \%)$ & $22(19.64 \%)$ & 0.274 \\
\hline
\end{tabular}

Note: Data are expressed as mean \pm SD, or numbers (\%).

Abbreviation: ERAS, enhanced recovery after surgery.

During the first $48 \mathrm{~h}$ after the operation, the incidence of nausea remained low in both the groups, without any significant difference between the two groups. There were no instances of postoperative vomiting. The incidence of pruritus in both groups was similar, with no significant intergroup difference.
Table 3 Postoperative Pain VAS

\begin{tabular}{|l|l|l|l|}
\hline Characteristics & $\begin{array}{l}\text { Group } \\
\text { Control } \\
\mathbf{n = 1 0 4}\end{array}$ & $\begin{array}{l}\text { Group } \\
\text { ERAS n= I I 2 }\end{array}$ & P value \\
\hline Rest in 24 h & $3.50 \pm 1.76$ & $2.46 \pm 1.58$ & $<0.00 \mathrm{I}$ \\
Motion in 24 h & $4.74 \pm 1.90$ & $3.38 \pm 2.10$ & $<0.00 \mathrm{I}$ \\
Rest in 48 h & $2.60 \pm 1.57$ & $2.00 \pm 1.65$ & 0.007 \\
Motion in 48 h & $3.50 \pm 1.65$ & $2.77 \pm 2.0 \mathrm{I}$ & 0.004 \\
Requirement of & $\mathrm{I}(0.96 \%)$ & $\mathrm{I}(0.89 \%)$ & 1.000 \\
extra analgesics & & & \\
\hline
\end{tabular}

Note: Data are expressed as mean $\pm S D$.

Abbreviations: VAS, visual analog scale; ERAS, enhanced recovery after surgery.

\section{Satisfaction VAS, Length of Stay and the Cost of Hospitalization (Table 5)}

The mean of patient satisfaction according to the VAS score in both groups was above 8 , but was significantly higher in the ERAS group.

While the length of stay and postoperative length of stay were comparable in the two groups, there were no intergroup differences in the cost of anesthesia. However, the average daily hospitalization cost was significantly lower in the ERAS group than in the control group.

\section{Discussion}

This prospective-randomized controlled trial demonstrated that ERAS protocols were useful in CD to alleviate postoperative pain, decrease the incidence of intraoperative complications such as nausea, improve maternal satisfaction, and reduce the average cost of hospitalization. However, the application of the ERAS protocol did not reduce the length of stay or incidence of other perioperative complications.

Pain is one of the main concerns of patients who undergo surgery. Effective perioperative analgesia is a key factor in

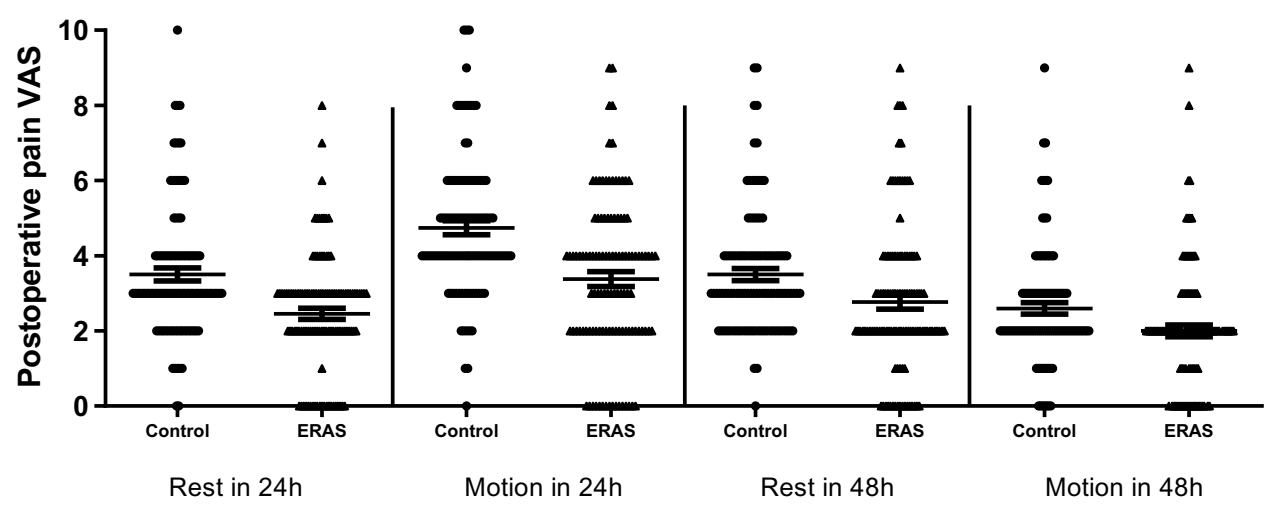

Figure 2 Visual analog scale (VAS) scores of pain in the two groups at rest and motion on the first and second postoperative days. 


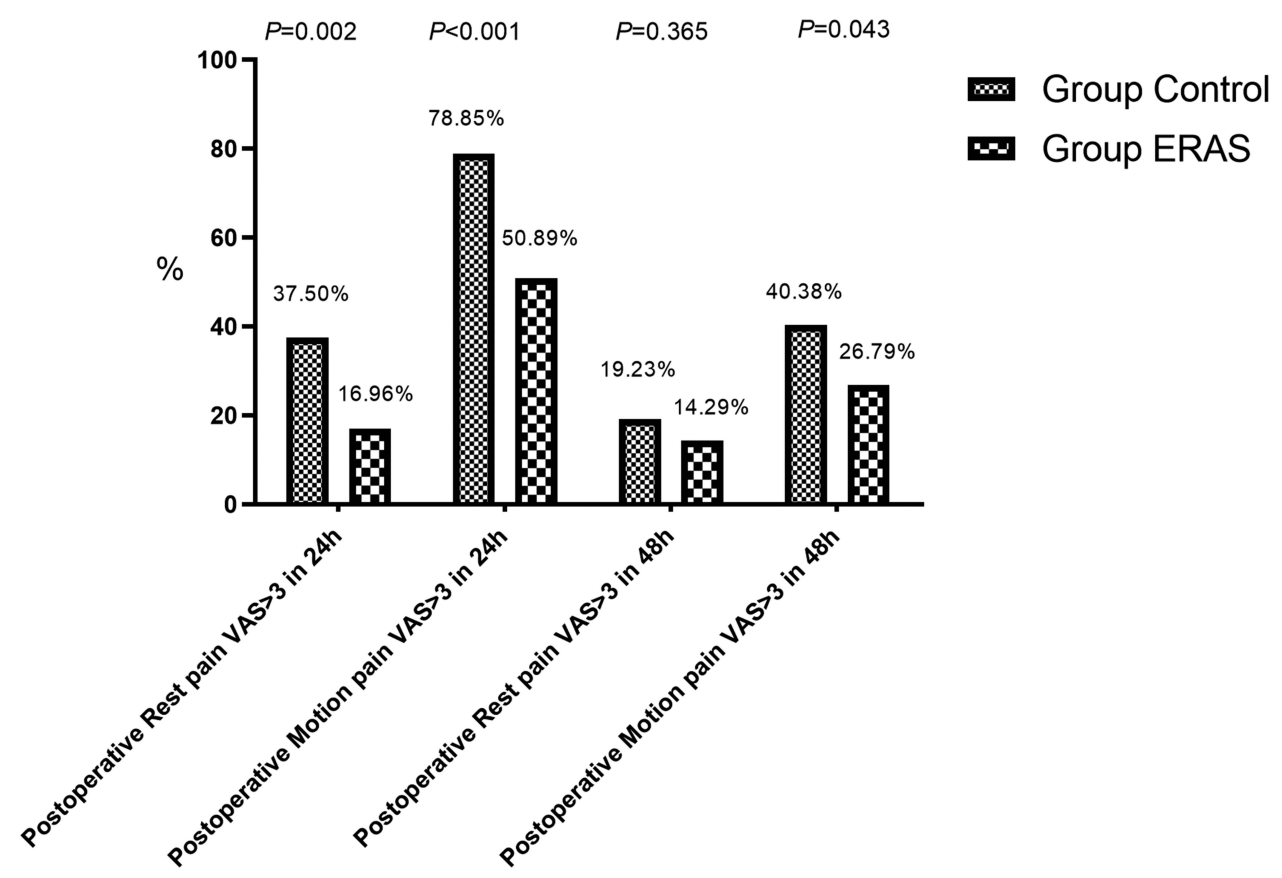

Figure 3 The proportion of postoperative pain of visual analog scale (VAS) grade $>3$ in the two groups.

facilitating postoperative function recovery and in successfully implementing the ERAS program. An analysis of pain severity over a hundred different surgical procedures revealed that post-CD pain intensity was one of the highest. ${ }^{12}$ Suboptimal analgesia has been shown to be associated with the failure of other components of ERAS, including delayed mobilization, delayed functional recovery, difficulties in breastfeeding and providing intimate contact to newborns, postpartum depression, and persistent pain. ${ }^{13}$ Adequate postoperative analgesia is an important and

Table 4 Intraoperative and Postoperative Conditions

\begin{tabular}{|c|c|c|c|}
\hline Characteristics & $\begin{array}{l}\text { Group } \\
\text { Control } \\
n=104\end{array}$ & $\begin{array}{l}\text { Group } \\
\text { ERAS } \\
n=1 \mid 2\end{array}$ & P value \\
\hline \multicolumn{4}{|l|}{ Intraoperative } \\
\hline $\begin{array}{l}\text { Carboprost } \\
\text { tromethamine }\end{array}$ & 82 (78.85\%) & $76(67.86 \%)$ & 0.091 \\
\hline Dexmedetomidine & 33 (31.73\%) & 66 (58.93\%) & $<0.001$ \\
\hline Nausea & $23(22.12 \%)$ & $3(2.68 \%)$ & $<0.001$ \\
\hline Vomiting & $6(5.77 \%)$ & I (0.89\%) & 0.058 \\
\hline Shivering & $8(7.69 \%)$ & 9 (8.04\%) & 1.000 \\
\hline Hypotension & 35 (33.65\%) & 31 (27.08\%) & 0.377 \\
\hline \multicolumn{4}{|l|}{$\begin{array}{l}\text { Postoperative } \\
\text { discomfort in } 48 \mathrm{~h}\end{array}$} \\
\hline Nausea & I (0.96\%) & $4(3.57 \%)$ & 0.371 \\
\hline Pruritus & 25 (24.04\%) & $28(25.00 \%)$ & 0.876 \\
\hline
\end{tabular}

integral component of ERAS protocol, which is achieved via a multidisciplinary approach. Multimodal analgesia refers to the approach of using a combination of drugs acting under different mechanisms as well as different interventional modalities to optimize analgesia and minimize side effects. ${ }^{14,15}$ Multimodal analgesia has been shown to have a positive effect in many non-obstetric surgical procedures, such as urologic, gastrointestinal, and orthopedic surgeries. ${ }^{15,16}$ However, the effect of multimodal analgesia in CD still remains controversial. Nonsteroidal antiinflammatory drugs (NSAIDs) are usually incorporated in multimodal analgesic protocols because of their relatively milder adverse effects and efficacy in anti-inflammatory

Table 5 Satisfaction VAS, Length of Stay, and the Cost of Hospitalization

\begin{tabular}{|c|c|c|c|}
\hline Characteristics & $\begin{array}{l}\text { Group } \\
\text { Control } \\
n=104\end{array}$ & $\begin{array}{l}\text { Group ERAS } \\
n=112\end{array}$ & $P$ value \\
\hline Satisfaction VAS & $8.12 \pm 1.08$ & $8.42 \pm 0.76$ & 0.016 \\
\hline Length of stay (d) & $4.61 \pm 0.64$ & $4.67 \pm 0.49$ & 0.412 \\
\hline $\begin{array}{l}\text { Postoperative length of } \\
\text { stay (d) }\end{array}$ & $3.42 \pm 0.55$ & $3.45 \pm 0.64$ & 0.775 \\
\hline $\begin{array}{l}\text { Average cost of } \\
\text { hospitalization (RMB/d) }\end{array}$ & $2140.4 \pm 335.4$ & $1568.2 \pm 303.8$ & $<0.001$ \\
\hline $\begin{array}{l}\text { The cost of anesthesia } \\
\text { (RMB) }\end{array}$ & $1047.9 \pm 221.1$ & $1045.6 \pm 212.8$ & 0.937 \\
\hline
\end{tabular}


and relief of visceral pain. Some investigators have shown that acetaminophen or NSAIDs could decrease the requirement of postoperative opioids, ${ }^{17}$ while others were of the opposite view. ${ }^{18,19}$ Transversus abdominis plane (TAP) blocks helped provide improved postoperative analgesia and reduce morphine consumption in patients who underwent $\mathrm{CD}$ under general anesthesia, ${ }^{20}$ but not in those who received intrathecal morphine. ${ }^{21}$ Compared to the standard analgesic regimen, TAP blocks do not have any effect in reducing the incidence or severity of chronic postsurgical pain after CD. ${ }^{22}$

In our study, neither perioperative oral and intravenous analgesics nor nerve blocks were requested designedly, and the same CSEA protocol was applied for all patients. PCEA was a countermeasure to withstand the wide interindividual variability in post-CD pain. Although less morphine was used in the ERAS group (6 mg vs. 6-7 mg), the mean of postoperative pain VAS scores was significantly lower, and patients with obvious pain (VAS $>3$ ) were significantly fewer than that in the control group. Therefore, it could be inferred that pain relief should be attributed to the overall ERAS strategy rather than morphine. Recent studies have shown that active patient participation during the perioperative period had a positive impact on the postoperative outcomes, including pain relief. ${ }^{15,23}$ In addition, dexmedetomidine was believed to decrease VAS scores. ${ }^{24}$ The reduced pain in the ERAS group may be attributed to the increased administration of dexmedetomidine in that group. Our results suggested that ERAS protocol can be employed as an alternative to analgesics in the future. However, there was another surprising finding that although a number of patients reported pain of $\mathrm{VAS}>3$, only one patient in each group requested for extra analgesics, which was considered to be avoided as far as possible. The reason might include that with outdated or traditional concepts, intrapartum and postpartum pain are considered unavoidable, and analgesics are considered to have adverse effect on infants through breastfeeding. Although these notions have gradually changed with preoperative education, it still remains deeply ingrained in the public mindset; therefore, better publicity and education of people regarding the newer concepts are warranted.

Increased analgesic effect is always accompanied by unfavorable adverse effects. Nausea, vomiting, and pruritus are the most common complications of $\mathrm{CD}$, especially in patients treated with neuraxial opioids. ${ }^{25}$ The risk of such complications has been reported to be lower with low doses of intrathecal morphine. ${ }^{26}$ Further, hypotension is one of the triggers of intraoperative nausea and vomiting in the mother. Currently, phenylephrine is considered as the optimal vasopressor to prevent hypotension since it is associated with a low incidence of intraoperative nausea and vomiting. ${ }^{27,28}$ Another complication, chills, has a complex and multifactorial etiology, including loss of body heat, response to pain, stimulation of the sympathetic nervous system, and anxiety. Further, more than $60 \%$ patients undergoing CD under spinal anesthesia develop hypothermia. ${ }^{29}$ Active warming helps improve hypothermia, thereby enhancing patient satisfaction and decreasing the length of stay after CD. ${ }^{30}$ As is the case with other surgeries, recent ERAS protocols for CD advocate the maintenance of perioperative normothermia. $^{10}$ Dexmedetomidine is recommended worldwide for the management of chills and cardiovascular response. ${ }^{31-33}$ Although the guidelines from ACOG do not the use of any preoperative sedatives, ${ }^{9}$ some studies have shown that the use of dexmedetomidine is effective in preventing adverse reactions, such as postoperative pain, shivering, nausea, vomiting, and chest congestion, especially those introduced by carboprost tromethamine, ${ }^{34-36}$ as well as alleviating postpartum depression. $^{37}$ Moreover, it has been proven safe for both mother and infant when used as an intravenous adjuvant during neuraxial anesthesia in parturients undergoing CD. ${ }^{38,39}$ Furthermore, in our practice, we have noted that low-dose dexmedetomidine $(0.5 \mu \mathrm{g} / \mathrm{kg})$ does not cause significant sedation in the mother or neonate; skin-to-skin contacting with the newborn, breastfeeding, and postoperative motion would not be disturbed.

Traditionally, patients are asked to fast for at least $12 \mathrm{~h}$ before the surgery to prevent vomiting and pulmonary aspiration after the surgery. However, recent studies have shown that reducing the fasting time not only reduced the extent of preoperative thirst, hunger, and insulin resistance, but also mitigated the anxiety and promote patient satisfaction. ${ }^{40,41}$ For the parturients awaiting elective caesarean, a short fasting time was associated with normal gastric emptying and safe. ${ }^{42}$ The multimodal beneficial effects of ERAS not only alleviate the concerns regarding the use of analgesics but also offer other advantages such as fetal protection, prevention of coagulopathy or blood loss, reduced risk of postpartum depression, and enhanced patient comfort.

Patient satisfaction is an important aspect of the assessment of medical services. Various factors can reduce patient satisfaction score. Apart from pain, adverse reactions, and wound healing, maternal concerns also include support from family and medical staff, the success of 
breastfeeding, and experience of skin-to-skin with the newborn. ${ }^{43}$ The implementation of an ERAS protocol is both a desirable and comprehensive solution to these problems. Furthermore, the application of ERAS enhances physician-patient communications, which would in turn help improve compliance, reduce anxiety, and enhance confidence.

The length of hospital stay is an important indicator of the outcome of using ERAS and the most visual indicator of recovery speed. Several studies recommend that with the application of the ERAS protocol, the median length of hospital stay could be reduced by $30 \%$ or at least 2 days in patients undergoing abdominal surgery, without increasing the risk of readmission. ${ }^{16,44,45}$ The application of ERAS in CD contributed to a reduction of $0.5-1.5$ days in postoperative length of stay. ${ }^{46}$ In our study, the length of hospital stay and length of postoperative hospital stay in both groups were around $4.6 \mathrm{~d}$ and $3.4 \mathrm{~d}$, respectively, which meant that the differences between the two groups were not significant. There may be several reasons for this. First, CD is widely used and relatively mature, and the incidence of postoperative complications has been very low at our medical center. Secondly, due to financial requirements such as insurance and reimbursement system, the length of stay for CD is already reduced to as low as possible and further reduction may be difficult. The reduction in the overall hospitalization costs reported previously was based on the reduction in the length of hospital stay. ${ }^{15,47,48}$ With respect to the average cost of daily hospitalization, few studies have shown that ERAS protocol is beneficial. Since ERAS involves the use of various treatment approaches, drugs, and medical care modalities, the average daily cost of implementing this protocol may not differ significantly from or may be slightly higher than that of routine protocols. However, our study revealed that the average daily cost in the ERAS group was significantly lower than that in the control group. These results are encouraging and would greatly promote the enthusiasm of medical professionals, patients, and insurance institutions towards the application of ERAS protocols. One of the reasons for this may be the improved comfort, which in turn would reduce the need for additional treatment and care. This would result in various advantages such as a reduction in the need for care workers because of the early postoperative mobility, decrease in the requirement of fluid infusion due to the early oral intake, and reduction in the extent of medical care for the newborn because of early skin-to-skin contact and breast-feeding. Further, the implementation of ERAS protocols helps enhance patients' understanding of the perinatal period, increases their sense of control, and confidence.

Our study has a few limitations. First, we did not include long-term evaluation of the prognosis, which would require sufficient post-discharge follow-up and/or community health care data. Second, a wider repertoire of adverse reactions and complications could be included in the analysis, since the popularization of ERAS warrants attention to not only familiar complications but also less harmful and uncommon adverse reactions. Finally, it may be possible to include fetal parameters in the analysis of the impact of ERAS on the fetus. We intend to conduct further research and analysis to address these issues.

\section{Conclusion}

In conclusion, the implementation of ERAS protocols in patients undergoing elective CD significantly reduced postoperative pain, facilitated perioperative pain management, reduced the incidence of intraoperative nausea as well as the average cost of hospitalization, and improved patient satisfaction. However, our results did not show any advantages of using ERAS protocols in terms of the length of stay and other perioperative discomforts. Nevertheless, considering the benefits, we recommend that it would be worthwhile to encourage the widespread implementation of ERAS protocols in patients undergoing elective CD.

\section{Registration}

This study has been registered in the Chinese Clinical Trial Registry (registration no.: ChiCTR1900025456, registered 26 August 2019, http://www.chictr.org.cn/showproj.aspx? proj=42067).

\section{Data Sharing Statement}

Individual deidentified participant data were made available. The data involved in the results were made available.

\section{Author Contributions}

Jingru Pan and Ziqing Hei: Substantial contributions to conception and design, data acquisition, or data analysis and interpretation. Drafting the article or critically revising it for important intellectual content. Final approval of the version to be published.

Liping Li, Dan Zhu, Hongying Hou, and Huizhen Wu: Data collection. Drafting the article or critically revising it for important intellectual content. 
Chulian Gong and Shaoli Zhou: Agreement to be accountable for all aspects of the work in ensuring that questions related to the accuracy or integrity of the work are appropriately investigated and resolved. Final approval of the version to be published.

All authors made substantial contributions to conception and design, acquisition of data, or analysis and interpretation of data; took part in drafting the article or revising it critically for important intellectual content; gave final approval of the version to be published; and agree to be accountable for all aspects of the work.

\section{Ethics and Consent Statement}

Ethical approval document and patient informed consent were made available but in Chinese. The way of sharing data: https://www.zssy.com.cn, or contacted with corresponding author.

The data were made available permanently for 3 months after the study.

\section{Disclosure}

The authors report no conflicts of interest in this work.

\section{References}

1. Boerma T, Ronsmans C, Melesse DY, et al. Global epidemiology of use of and disparities in caesarean sections. Lancet. 2018;392 (10155):1341-1348. doi:10.1016/S0140-6736(18)31928-7

2. Lumbiganon P, Laopaiboon M, Gulmezoglu AM, et al. Method of delivery and pregnancy outcomes in Asia: the WHO global survey on maternal and perinatal health 2007-08. Lancet. 2010;375 (9713):490-499. doi:10.1016/S0140-6736(09)61870-5

3. Quinlan JD, Murphy NJ. Cesarean delivery: counseling issues and complication management. Am Fam Physician. 2015;91(3):178-184.

4. Li J-X. Pain and depression comorbidity: a preclinical perspective. Behav Brain Res. 2015;276:92-98. doi:10.1016/j.bbr.2014.04.042

5. Pedziwiatr M, Pisarska M, Wierdak M, et al. The use of the Enhanced Recovery After Surgery (ERAS) protocol in patients undergoing laparoscopic surgery for colorectal cancer-a comparative analysis of patients aged above 80 and below 55. Pol Przegl Chir. 2015;87(11):565-572. doi:10.1515/pjs-2016-0004

6. Kehlet H. Multimodal approach to control postoperative pathophysiology and rehabilitation. $B r J$ Anaesth. 1997;78(5):606-617. doi:10.1093/bja/78.5.606

7. Kehlet H. Fast-track colorectal surgery. Lancet. 2008;371 (9615):791-793. doi:10.1016/S0140-6736(08)60357-8

8. Slim K, Kehlet H. Commentary: fast track surgery: the need for improved study design. Colorectal Dis. 2012;14(8):1013-1014. doi:10.1111/j.1463-1318.2012.03114.x

9. Wilson RD, Caughey AB, Wood SL, et al. Guidelines for antenatal and preoperative care in cesarean delivery: enhanced recovery after surgery society recommendations (Part 1). Am J Obstet Gynecol. 2018;219(6):523.e521-523.e515. doi:10.1016/j.ajog.2018.09.015

10. Caughey AB, Wood SL, Macones GA, et al. Guidelines for intraoperative care in cesarean delivery: enhanced recovery after surgery society recommendations (Part 2). Am J Obstet Gynecol. 2018;219 (6):533-544. doi:10.1016/j.ajog.2018.08.006
11. Macones GA, Caughey AB, Wood SL, et al. Guidelines for postoperative care in cesarean delivery: Enhanced Recovery After Surgery (ERAS) society recommendations (part 3). Am J Obstet Gynecol. 2019;221(3):247.e241-247.e249. doi:10.1016/j.ajog.2019.04.012

12. Gerbershagen HJ, Aduckathil S, van Wijck AJM, Peelen LM, Kalkman CJ, Meissner W. Pain intensity on the first day after surgery: a prospective cohort study comparing 179 surgical procedures. Anesthesiology. 2013;118(4):934-944. doi:10.1097/ALN.0b013e3182 $8866 \mathrm{~b} 3$

13. Eisenach JC, Pan PH, Smiley R, Lavand'homme P, Landau R, Houle TT. Severity of acute pain after childbirth, but not type of delivery, predicts persistent pain and postpartum depression. Pain. 2008;140(1):87-94. doi:10.1016/j.pain.2008.07.011

14. American Society of Anesthesiologists Task Force on Acute Pain Management. Practice guidelines for acute pain management in the perioperative setting: an updated report by the American Society of Anesthesiologists Task Force on acute pain management. Anesthesiology. 2012;116(2):248-273. doi:10.1097/ALN.0b013e31 $823 \mathrm{c} 1030$

15. Kalogera E, Dowdy SC. Enhanced recovery pathway in gynecologic surgery: improving outcomes through evidence-based medicine. Obstet Gynecol Clin North Am. 2016;43(3):551-573. doi:10.1016/j. ogc.2016.04.006

16. Yang R, Tao W, Chen -Y-Y, et al. Enhanced recovery after surgery programs versus traditional perioperative care in laparoscopic hepatectomy: a meta-analysis. Int J Surg. 2016;36(Pt A):274-282. doi:10.1016/j.ijsu.2016.11.017

17. Altenau B, Crisp CC, Devaiah CG, Lambers DS. Randomized controlled trial of intravenous acetaminophen for postcesarean delivery pain control. Am J Obstet Gynecol. 2017;217(3):362.e361-362.e366. doi:10.1016/j.ajog.2017.04.030

18. Hadley EE, Monsivais L, Pacheco L, et al. Multimodal pain management for cesarean delivery: a double-blinded, placebo-controlled, randomized clinical trial. Am J Perinatol. 2019;36(11):1097-1105. doi:10.1055/s-0039-1681096

19. Towers CV, Shelton S, van Nes J, et al. Preoperative cesarean delivery intravenous acetaminophen treatment for postoperative pain control: a randomized double-blinded placebo control trial. $\mathrm{Am}$ J Obstet Gynecol. 2018;218(3):353 e351-353 e354. doi:10.1016/j. ajog.2017.12.203

20. Tan T, Teoh WHL, Woo DCM, Ocampo CE, Shah MK, Sia ATH. A randomised trial of the analgesic efficacy of ultrasound-guided transversus abdominis plane block after caesarean delivery under general anaesthesia. Eur $J$ Anaesthesiol. 2012;29(2):88-94. doi:10.1097/EJA.0b013e32834f015f

21. Abdallah FW, Halpern H, Margarido CB. Transversus abdominis plane block for postoperative analgesia after caesarean delivery performed under spinal anaesthesia? A systematic review and meta-analysis. $\mathrm{Br}$ J Anaesth. 2012;109(5):679-687. doi:10.1093/bja/aes279

22. Borys M, Potręć-Studzińska B, Wiech M, et al. Transversus abdominis plane block and quadratus lumborum block did not reduce the incidence or severity of chronic postsurgical pain following cesarean section: a prospective, observational study. Anaesthesiol Intensive Ther. 2019; undefined(undefined):undefined.

23. Poland F, Spalding N, Gregory S, McCulloch J, Sargen K, Vicary P. Developing patient education to enhance recovery after colorectal surgery through action research: a qualitative study. BMJ Open. 2017;7(6):e013498. doi:10.1136/bmjopen-2016-013498

24. Gurbet A, Basagan-Mogol E, Turker G, Ugun F, Kaya FN, Ozcan B. Intraoperative infusion of dexmedetomidine reduces perioperative analgesic requirements. Can J Anaesth. 2006;53(7):646-652. doi:10.1007/BF03021622

25. Griffiths JD, Gyte GM, Paranjothy S, Brown HC, Broughton HK, Thomas J. Interventions for preventing nausea and vomiting in women undergoing regional anaesthesia for caesarean section. Cochrane Database Syst Rev. 2012; undefined(9):CD007579. 
26. Sultan P, Halpern SH, Pushpanathan E, Patel S, Carvalho B. The effect of intrathecal morphine dose on outcomes after elective cesarean delivery: a meta-analysis. Anesth Analg. 2016;123(1):154-164. doi:10.1213/ANE.0000000000001255

27. George RB, McKeen M, Dominguez JE, Allen TK, Doyle PA, Habib AS. A randomized trial of phenylephrine infusion versus bolus dosing for nausea and vomiting during cesarean delivery in obese women. Can J Anaesth. 2018;65(3):254-262. doi:10.1007/ s12630-017-1034-6

28. Xu C, Liu S, Huang Y, Guo X, Xiao H, Qi D. Phenylephrine vs ephedrine in cesarean delivery under spinal anesthesia: a systematic literature review and meta-analysis. Int $J$ Surg. 2018;60 (undefined):48-59. doi:10.1016/j.ijsu.2018.10.039

29. Ituk U, Habib AS. Enhanced recovery after cesarean delivery. F1000Research. 2018;7(undefined):undefined.

30. Wrench IJ, Allison A, Galimberti A, Radley S, Wilson MJ. Introduction of enhanced recovery for elective caesarean section enabling next day discharge: a tertiary centre experience. Int J Obstet Anesth. 2015;24 (2):124-130. doi:10.1016/j.ijoa.2015.01.003

31. Lamontagne C, Lesage S, Villeneuve E, Lidzborski E, Derstenfeld A, Crochetière $\mathrm{C}$. Intravenous dexmedetomidine for the treatment of shivering during cesarean delivery under neuraxial anesthesia: a randomized-controlled trial. Can J Anaesth. 2019;66(7):762-771. doi:10.1007/s12630-019-01354-3

32. Liu J, Wang Y, Ma W. Shivering prevention and treatment during cesarean delivery under neuraxial anesthesia: a systematic review. Minerva Anestesiol. 2018;84(12):1393-1405. doi:10.23736/S03759393.18.12478-3

33. Ao L, Shi J, Bai Y, Zheng Y, Gan J. Effectiveness and safety of intravenous application of dexmedetomidine for cesarean section under general anesthesia: a meta-analysis of randomized trials. Drug Des Devel Ther. 2019;13:965-974. doi:10.2147/DDDT. S197165

34. Bao Z, Zhou C, Wang X, Zhu Y. Intravenous dexmedetomidine during spinal anaesthesia for caesarean section: a meta-analysis of randomized trials. J Int Med Res. 2017;45(3):924-932. doi:10.1177/ 0300060517708945

35. Nie Y, Tu W, Shen X, et al. Dexmedetomidine added to sufentanil patient-controlled intravenous analgesia relieves the postoperative pain after cesarean delivery: a prospective randomized controlled multicenter study. Sci Rep. 2018;8(1):9952. doi:10.1038/s41598018-27619-3

36. Liu Y, Chen H-X, Kang D-L, Kuang X-H, Liu W-X, Ni J. Influence of dexmedetomidine on incidence of adverse reactions introduced by hemabate in postpartum hemorrhage during cesarean section. Int J Clin Exp Med. 2015;8(8):13776-13782.
37. Yu Y, Wang S-Y, Quan C-X, et al. Dexmedetomidine alleviates postpartum depressive symptoms following cesarean section in Chinese women: a randomized placebo-controlled study. Pharmacotherapy. 2019;39(10):994-1004. doi:10.1002/phar.2320

38. Zhang Y-W, Zhang J, Hu J-Q, et al. Neuraxial adjuvants for prevention of perioperative shivering during cesarean section: a network meta-analysis following the PRISMA guidelines. World J Clin Cases. 2019;7(16):2287-2301. doi:10.12998/wjcc.v7.i16.2287

39. Yoshimura M, Kunisawa T, Suno M, et al. Intravenous dexmedetomidine for cesarean delivery and its concentration in colostrum. Int J Obstet Anesth. 2017;32:28-32. doi:10.1016/j.ijoa.2017.05.002

40. Noba L, Wakefield A. Are carbohydrate drinks more effective than preoperative fasting: a systematic review of randomised controlled trials. J Clin Nurs. 2019;28(17-18):3096-3116. doi:10.1111/jocn.14919

41. Karimian N, Kaneva P, Donatelli F, et al. Simple versus complex preoperative carbohydrate drink to preserve perioperative insulin sensitivity in laparoscopic colectomy: a randomized controlled trial. Ann Surg. 2019; undefined(undefined):undefined.

42. Popivanov P, Irwin R, Walsh M, Leonard M, Tan T. Gastric emptying of carbohydrate drinks in term parturients before elective caesarean delivery: an observational study. Int J Obstet Anesth. 2019;undefined (undefined):undefined.

43. Moore ER, Bergman N, Anderson GC, Medley N. Early skin-to-skin contact for mothers and their healthy newborn infants. Cochrane Database Syst Rev. 2016;11(undefined):CD003519. doi:10.1002/ 14651858.CD011360.pub2

44. Wang L-H, Zhu R-F, Gao C, Wang S-L, Shen L-Z. Application of enhanced recovery after gastric cancer surgery: an updated meta-analysis. World J. Gastroenterol. 2018;24(14):1562-1578. doi:10.3748/wjg.v24.i14.1562

45. Greco M, Capretti G, Beretta L, Gemma M, Pecorelli N, Braga M. Enhanced recovery program in colorectal surgery: a meta-analysis of randomized controlled trials. World J Surg. 2014;38(6):1531-1541. doi:10.1007/s00268-013-2416-8

46. Corso E, Hind D, Beever D, et al. Enhanced recovery after elective caesarean: a rapid review of clinical protocols, and an umbrella review of systematic reviews. BMC Pregnancy Childbirth. 2017;17 (1):91. doi:10.1186/s12884-017-1265-0

47. Liao Z, Liao W, Tan KS, et al. Decreased hospital charges and postoperative pain in septoplasty by application of enhanced recovery after surgery. Ther Clin Risk Manag. 2018;14(undefined):1871-1877. doi:10.2147/TCRM.S173687

48. Stowers MD, Manuopangai L, Hill AG, Gray JR, Coleman B, Munro JT. Enhanced recovery after surgery in elective hip and knee arthroplasty reduces length of hospital stay. ANZ J Surg. 2016;86 (6):475-479. doi:10.1111/ans. 13538
Therapeutics and Clinical Risk Management

\section{Publish your work in this journal}

Therapeutics and Clinical Risk Management is an international, peerreviewed journal of clinical therapeutics and risk management, focusing on concise rapid reporting of clinical studies in all therapeutic areas, outcomes, safety, and programs for the effective, safe, and sustained use of medicines. This journal is indexed on PubMed Central, CAS,

\section{Dovepress}

EMBase, Scopus and the Elsevier Bibliographic databases. The manuscript management system is completely online and includes a very quick and fair peer-review system, which is all easy to use. Visit http://www.dovepress.com/testimonials.php to read real quotes from published authors. 